\title{
Continued Root End Growth and Closure of Immature Apices in Molar Using Metapex Paste: A Case Report
}

\author{
Jain K., M.D.S ${ }^{1}$, Dubey A., M.D.S ${ }^{2 *}$, Avinash A., M.D.S ${ }^{1}$, Mujoo S., M.D.S ${ }^{2}$ \\ ${ }^{I}$ Pediatric dentistry, Senior Lecturer, Rungta College of Dental Sciences, Bhilai, India \\ ${ }^{1}$ Pediatric dentistry, Associate professor, Rungta College of Dental Sciences, Bhilai, India \\ ${ }^{2}$ Pediatric dentistry, Associate professor, College of Dentistry, Jazan University, Jazan, Saudi Arabia \\ ${ }^{2}$ Oral Medicine \& Radiology, Assistant Professor, College of Dentistry, Jazan University, Jazan, Saudi Arabia \\ *Corresponding Author: Dr. Alok Dubey, Associate Professor (Department of Pedodontics \& \\ Preventive dentistry), College of Dentistry, Jazan University, Jazan, Saudi Arabia. Email: dentaalok@ \\ yahoo.com
}

\begin{abstract}
Basic aim of root canal treatment is to fill the root canal system completely in order to prevent reinfection. But, it is not possible to achieve a good apical and lateral seal due to an open apex and an abnormal width and shape of root canal. Endodontic treatment options consist of apical barriers, apexification or more recently, revascularization. The purpose of this case report is to present a treatment to promote root-end growth and apexification in a non-vital immature permanent molar. A case is presented where the calcium hydroxide and idoform paste (Metapex) was placed in root canals of immature non-vital tooth to achieve apexification process. There was resolution of periapical radiolucency and root end closure after 6 months. Metapex shows good clinical and radiographic success in promoting continued root growth and inducing root end closure even in immature necrotic young posteriorpermanent teeth.
\end{abstract}

Keywords: Apexification, Apical closure, Metapex

\section{INTRODUCTION}

Interrupted root canal development and lack of apical closure makes conventional endodontic treatment difficult to be performed in necrotic immature teeth. In the past, pulp less teeth with open apex had been managed by custom fitting the filling materials with or without apical surgery and retrograde filling procedures. The thin dentinal walls and unfavorable crown-root ratio of immature teeth further result in short, weak tooth with doubtful prognosis (Rafter M, 2005).In this situation the standard therapeutic approach called apexification procedure has been used.

Early evidence suggests the osteo-inductive properties of calcium hydroxide (Mitchell and Shankwalkar, 1958). Considering this property of calcium hydroxide, apexification in a nonvital permanent incisor was introduced. (Kaiser, 1962; Frank, 1966). Apical root closure and bone healing was observed following intracanal placement of calcium hydroxide $\left(\mathrm{CaOH}_{2}\right)$ in 50 of 55 maxillary incisors with immature roots (Cvek, 1972). From the histological stand point, the calcified material that forms over the apical foramen has been identified as ancementoid or osteoid material (Steiner and Hassel, 1971; Dylewski, 1971).

Despite its popularity for the apexification procedure, calcium hydroxide has some disadvantages therefore search continues for alternative material that promote more natural root end closure; like metapex (calcium hydroxide with idoform formulations) (Sridhar and Tandon, 2010), mineral trioxide aggregate (Pace et al., 2007).Revascularization of permanent necrotic immature tooth can also be done by stimulating blood clot from the periapical tissues into the canal space (McTigueet al., 2013).

A mixture of calcium hydroxide and idoform paste has been used as a root canal filling material in primary teeth with good clinical and radiographic success. But few studies reports its 
use in apexification procedure (Sridhar and Tandon, 2010; Lu and Qin, 2004; Weng, 2004).

Apexification procedures are often undertaken in necrotic immature permanent anterior teeth but few case have been reported in posterior permanent teeth. This article report a case in which the calcium hydroxide and idoform paste (Metapex) was used successfully to promote root-end growth and apical closure in the permanent molar tooth of a child.

\section{CASe Report}

A healthy 10-year-old boy reported to the department with the chief complaint of pain in lower left back tooth region since 5 days. Clinical examination revealed deep carious lesion in left mandibular first permanent molar (tooth no 36) and was found to be tender on percussion. Radiographic examination revealed periapical radiolucency in relation to incompletely formed mesial and distal root apices in tooth \# 36 (fig 1A). After clinical and radiographic examination, diagnosis of symptomatic apical periodontitis was made. Apexification procedure was recommended for tooth \# 36.

The tooth was anesthetized with $2 \%$ lidocaine with 1:80,000 epinephrine, isolation and access opening was done and the necrotic pulp tissue was removed with a barbed broach. Working length was determined and instrumentation was performed with circumferential filing motion, aided by copious irrigation with saline and $5.25 \%$ sodium hypochlorite $(\mathrm{NaOCl})$. Sterile paper points were used to dry the canal and were filled with calcium hydroxide and idoform paste (Metapex) by using disposable plastic tips provided in the kit. The occlusal surface was sealed with a provisional material (Cavit TM, 3M ESPE, St. Paul, MN, USA. An immediate post-operative radiograph was taken to assess the extent and placement of materials in the root canals.

Child's progress for apexification was followed for 2 and 4 months and 6months (Fig 1B) and apical barrier was confirmed by gutta-percha cones (Fig 1C). At the end of 6 months there was an increase in root length, so conventional root canal treatment was performed (Fig 1D). The tooth was then restored with silver amalgam.

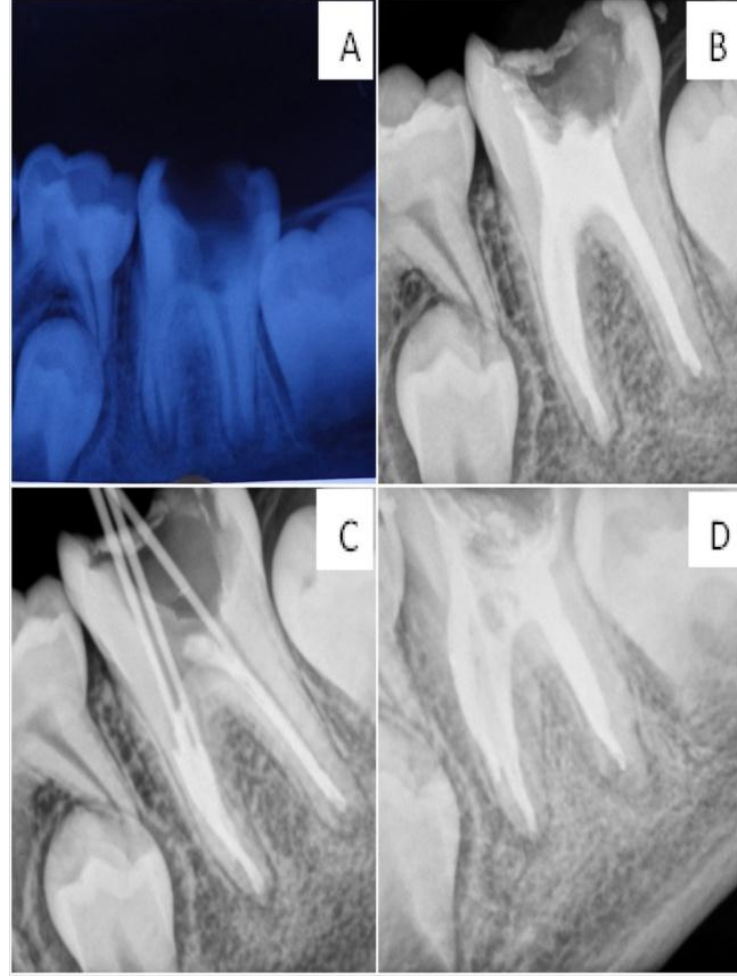

Figure1. Showing the (A) Preoperative radiograph of tooth \# 36 showing immature roots and periapical radiolucency (B) Metapex in the canal for apexification procedure (C) Guttapercha cone for checking apical calcific bridge (D) obturation of tooth \# 36.

\section{DISCUSSION}

Apexification can be defined as a "method to induce a calcific barrier in a root with an open apex or the continued apical development of teeth with incomplete roots and a necrotic pulp." (American Association of Endodontics 2003). This calcified barrier may be of osteocementum or other bone like tissue (Grossman 1988).

The procedure involves canal cleaning and shaping or the removal of all necrotic tissue, and hermetic sealing of the tooth by placement of suitable material to the apex to avoid bacterial infilteration. The prime importance of apexification procedure is to achieve an apical stop for compaction of obturating material (Mohammadiand Dummer, 2011).

Various materials have been used for the apexification of nonvital permanent teeth such as Zinc oxide-iodoform (Cooke and Rowbotham, 1960), resorbabletri calcium phosphate (Koenigset al., 1975), calcium hydroxide based materials (Kaiser, 1964; Frank, 1966; Cvek, 1972), Walkhoff's antiseptic paste (Bouchoan, 1966), polyantibiotic paste (Ball, 1964), or without any inducement material at all 
(England and Best, 1977), Vitapex(Lu and Qin, 2004).

Calciumhydroxide has been the first choice material for apexification because of its antimicrobial action on bacterial cellular components mainly on lipopolysaccharide (LPS) (Jiang et al., 2003) and its high pH causes induction of hard tissue formation (Javelet et al., 1985). According to Kleier\& Barr (1991) apexification procedure can be achieved in 6-24 months (average 1 year \pm 7 months) and refilling of material every 3-6 months is favoured (Tronstad et al. 1981) however other reports shows radiographic evidence of refilling only if there is resorption of the paste (Cohen and Burns, 2002). In our case closure was achieved at 6 months following apexification.

Vitapex paste has been found to be an effective material for achieving apexification for younger permanent teeth (Weng, 2004). Uptil now only four studies were done using calcium hydroxide idoform paste as a medicament for apexification procedure. In this only two cases have been performed till date in molar. This report describes the use combination of calcium hydroxide and idoform paste (Metapex) to induce apexification process.

Apical barrier that formed are reported to be porous or of a "Swiss Cheese Configuration", and was described as cap, bridge or ingrown wedge composed of cementum, dentin, bone or osteodentin (Jyothi, 2012). According to Grossman (1988), matrix formation and subsequent calcification is guided by residual undamaged pulp tissue and their respective odontoblastic layer and reactivated Hertwig epithelial root sheath (HERS). Other evidence suggests that barrier formation depends on the extent of pulp necrosis at the time of treatment (Pitt Ford TR 2002) ${ }^{11}$. This report shows both clinical and radiographic success in achieving apexification. Unlike with barrier formation, continued root growth was observed for the treated tooth. Similar finding of root development and apical closure was noted in seven teeth treated with vitapex paste (Gu et al. $2007)^{12}$.

Till date, all the reported cases of molar apexification procedure have been completed in 12-13 months $^{4,5}$. Our case was unique in the sense that the apical closure was achieved in shortest possible span of 6 months.

\section{CONClusion}

Metapex shows good clinical and radiographic success in promoting continued root growth and inducing root end closure in immature necrotic young permanent teeth.

\section{REFERENCES}

[1] Ball JS. Apical root formation in nonvital immature permanent incisor. Report of a case. Br Dent J 1964; 116:166-7.

[2] Bouchon F. Apex formation following treatment of necrotized immature permanent incisor. J Dent Child 1966; 33:378-80.

[3] Cohen S, Burns RC. Pathways of the pulp, 8th edn. Mosby; 2002.

[4] Cooke C, Rowbotham TC. Root canal therapy in non-vital teeth with open apices. British Dental Journal 1960; 108:147-50.

[5] Cvek M. Treatment of non-vital permanent incisors with calcium hydroxide. I. Follow-up of periapical repair and apical closure of immature roots. Odonotol Revy 1972; 23:2744.

[6] Dylewski JJ. Apical closure of non-vital teeth. Oral Surgery 1971; 32:82-9.

[7] Frank AL. Therapy for divergent pulpless tooth by continued apical formation. Journal of American Dental Association 1966; 72:87-93.

[8] Grossman LI. Endodontic Practice. $11^{\text {th }}$ edn. Philadelphia PA: Lea and Febiger; 1988.

[9] Gu HJ, Xu Q, Liu LM, Ouyang Y. Treatment of chronic apical periodontitis teeth complicated by open apices with Vitapex in the adults. Shanghai Kou Qiang Yi Xue 2007; 16:140-3.

[10] Javelet J, Torabinejad M, Bakland LK. Comparison of two $\mathrm{pH}$ levels for the induction of apical barriers in immature teeth of monkeys. Journal of Endodontics 1985; 11:375-8.

[11] Jiang J, Zuo J, Chen SH, Holliday LS. Calcium hydroxide reduces lipopolysaccharidestimulated osteoclast formation. Oral Surgery, Oral Medicine, Oral Pathology, Oral Radiology and Endodontics 2003; 95:348-54.

[12] Jyothi M. Management of immature teeth - A paradigm shift from apexification to apexogenesis. Annals and Essences of Dentistry 2012; 4:34-38.

[13] Kaiser HJ. Management of wide open apex canals with calcium hydroxide. Presented at the $21^{\text {st }}$ Annual Meeting of the American Association of Endodontists, Washington DC, April 171964.

[14] Kleier DJ, Barr ES. A study of endodonticallyapexified teeth. Endodontics\& Dental Traumatology 1991; 7:112-8. 
[15] Koenigs JF, Heller AL, Brilliant JD, Melfi RC, Driskell TD. Induced apical closure of permanent teeth in adult primates using a resorbable form of tricalcium phosphate ceramic. J Endod 1975; 1:102-6.

[16] Lu YM, Qin JN. A comparison of the effect between vitapex paste and antibiotic paste in apexification. Shanghai Kou Qiang Yi Xue 2004; 13:449-51.

[17] McTigue DJ, Subramanian, Kumar A. Management of immature permanent teeth wirh pulpal necrosis: A case series. Pediatric Dentistry 2013; 35:55-60.

[18] Mohammadi Z, Dummer PMH. Properties and applications of calcium hydroxide in endodontics and dental traumatology. International Endodontic Journal 2011; 44:697730 .

[19] Pace R, Giuliani V, Pini Prato L, Baccetti T, Pagavino G. Apical plug technique using mineral trioxide aggregate: results from a case series. International Endodontic Journal 2007; 40:478-84.
[20] Pitt Ford TR. Apexification and apexogenesis. In: Walton RE, Torabinejad M, eds. Principles and practice of endodontics, 2nd edn. Philadelphia, PA: WB Saunders; 2002.

[21] Rafter M. Apexification: a review. Dent Traumatol 2005; 21:1-8.

[22] Sridhar N, Tandon S. Continued root-end growth and apexification using a calcium hydroxide and idoform paste (Metapex): Three case reports. Journal of Contemporary Dental practice 2010; 11:1-8.

[23] Steiner JC, Van Hassel HJ. Experimental root apexification in primates. Oral Surgery 1971; 31:409-15.

[24] Tronstad L, Andreasen JO, Hasselgren G, Kristenson L, Riis I. PH changes in dental tissues after root canal filling with calcium hydroxide. Journal of Endodontics 1981; 7:1721.

[25] Weng QF. Clinical study on the effect of Vitapex paste in apexification. Hua $\mathrm{Xi}$ Kou Qiang Yi XueZaZhi 2004; 22:214-5.

Citation: Jain K., M.D.S, Dubey A., M.D.S, Avinash A., M.D.S, Mujoo S., M.D.S. Continued Root End Growth and Closure of Immature Apices in Molar Using Metapex Paste: A Case Report. ARC Journal of Dental science. 2017; 2(2): 10-13. doi:dx.doi.org/10.20431/2456-0030.0202003.

Copyright: (c) 2017 Authors. This is an open-access article distributed under the terms of the Creative Commons Attribution License, which permits unrestricted use, distribution, and reproduction in any medium, provided the original author and source are credited. 